\title{
SMALLHOLDER FARMERS' AND THE TREATMENT OF LIVESTOCK DISEASES USING ETHNO-VETERINARY MEDICINE (EVM): A REVIEW AND COMMENTARY
}

\author{
${ }^{*}{ }_{1}$ Nwafor Christopher Ugochukwu \\ ${ }^{2}$ Nwafor Ifeoma Chinyelu \\ manchrizzo@hotmail.com* \\ ${ }^{1}$ Department of Agriculture, Central University of Technology, South Africa \\ ${ }^{2}$ Centre for Food Safety and Biotechnology, Central University of Technology, South Africa.
}

\begin{abstract}
Often touted as an ancient and sustainable practice among indigenous livestock farmers in developing countries, the use of ethno-veterinary medicine is examined within the context of its efficacy. While there are undoubtedly positive implications for adopting knowledge and practice that align with nature, there is both prevalence and ambivalence to the adoption of indigenous plant knowledge and resources for the treatment of livestock infections and diseases. This situation is due to the lack of validation and standardization of the practice in low-income countries, requiring scholarly efforts in developing this indigenous knowledge system.
\end{abstract}

Keywords: efficacy, ethno-veterinary, livestock, medicine, smallholder farmer

\section{Introduction}

The use of local plants in the treatment of farm animals has been the subject of scrutiny among livestock farmers, scholars and the research community. This as reported is partly due to the increasing demand for healthier organic alternatives, such as pasture-fed livestock and products free from synthetic materials like antibiotics, antimicrobial and other chemical concoctions. Furthermore, there is current attention to ethically raised farm animals by consumers willing to pay premium prices for livestock products from certified farm sources (Mayer 2014), and the heightened awareness occasioned by animal-rights activism. The use of plant-derived remedy is also given further impetus by the rising financial costs associated with treating livestock infections and diseases using orthodox practices, high cost of drugs and other medication, including fees payable to veterinarians and local animal health technicians. The Food and Agriculture Organization (2010) estimates losses of more than $35 \%$ due to diseases in the livestock sector among smallholder farmers in developing countries, and farmers resort to alternative practices is a way to reduce these losses from animal infections and diseases. Huffman (2016) averred that this practice follows the observation that animals, in their natural habitat, consume certain plants in order to derive relief from various ailments afflicting them.

There is however no definitive status on the utilization of this practice among the mainly rural owners of livestock, especially in the developing, low-income countries in Africa 
and Asia. While there is an abundance of studies within the area of ethno-veterinary medicine, many of these studies provide a narrative on possible application and a botanical description of plant materials collected and used by traditional practitioners and farmers to treat various ailments and diseases of production livestock. The current state of practice in the treatment of livestock diseases is therefore in need of review. What then, is the direction and status of ethnoveterinary medicine in low-income or developing countries?

\section{Methodology}

The review adopts a brief literature survey along key themes related to ethno-veterinary medicine use among rural smallholder livestock farmers. The main themes include factors driving adoption, availability of treatment alternatives, the demographic profile of users and current challenges faced in the application of ethno-veterinary medicine for treating livestock infections and diseases.

\section{Key Findings and Discussion}

Adapting local knowledge of plants and the practices associated with this has been welldocumented in the literature. The totality of the indigenous local animal healthcare beliefs and practices is popularly referred to as ethno-veterinary medicine (EVM), and the practice is reported in various continents both in the developed and developing countries. The importance of traditional animal health care practices in developing countries is noted, it has also morphed into a recognized field of research which includes veterinary theories, medication and surgery, including various diagnostic procedures as well as animal husbandry practices. The rising interest in the development of new pharmaceutical products, including the threat from climate change to vegetation and diversity of flora has ignited concern and scholarship in ethno-botany, novel phytotherapeutic products, cultural and medicinal resources. Considering the distinctive pharmacological nature of properties derived from plants in treating animal infections and diseases (McGaw and Abdalla, 2020), there is a growing call for the use of plant-derived metabolites as healthier alternatives to synthetic agents in livestock production activities.

Among rural smallholder livestock farmers in many sub-Sahara African countries, the use of ethno-veterinary practice and product is prevalent. Many livestock owners use herbal remedies where conventional knowledge is lacking, veterinary services are not easily available, or the cost of these services are unaffordable. The availability and affordability of alternative remedies has been noted by Raikwar and Maurya (2015) as a key factor driving use of ethno-veterinary medicine among rural livestock owners. Notwithstanding its availability, many livestock owners still utilize orthodox treatments for livestock, ascribing this to unsatisfactory experience in using herbal remedies, or, their perception of the practice as outdated and ineffective. Many others also use a combination of orthodox treatments and 
ethno-veterinary medicine to treat their livestock

Within the past decade, there has been an uptick in the research of ethno-veterinary medicine and practice. Many of these studies have been in developing countries, where conventional veterinary services and products carry high costs, and many government-run livestock health services have been privatized leaving rural smallholder farmers to deal directly with private sector providers at their own cost. The emphasis of these studies has been on the documentation of different plant materials utilized in the treatment of various livestock infections and diseases (Chitura et al. 2018). A key theme binding the literature on EVM in developing countries is a lack of demonstration of their potency. Various scholars point to important gaps in the quality evaluation of medicinal plants in relation to its authenticity, toxicity and consistency. Mafimisebi et al (2017) hence noted the significant shortcomings of traditional medicines when their preparation, presentation, efficacy, disease diagnosis and treatment specifications are scrutinized. These shortcomings have prompted the call for validation of traditional medicinal products (Sanhokwe et al. 2016), as there is a lack of consensus on the actual efficiency of various treatments. It has also been reported that some farmers have failed to use EVM due to poor knowledge of application rates, inadequate diagnosis, lack of documentation and side effects of the concoctions, as some of the challenges hindering their use of ethno- veterinary medicinal products (Mudzengi et al. 2014).

The general description or a clear profile of users and adopters of ethno-veterinary products and practices in the literature is discernible. In the developed economies, farmers may utilize such phyto-therapeutic products in order to comply with directives for organic livestock treatment (Mayer et al., 2017). Many studies in developing countries report its popularity among rural livestock owners, who practice the extensive (freerange) farming system, primarily relying on accessible communal pastures, and are resource-constrained. Their dependence on herbs and plant materials gathered from the wild, suggests an inability to afford conventional veterinary services and products, including the unavailability within the rural community of these established services. Additionally, there is a cultural perspective to the demography of reported users, indicating its relationship to traditional beliefs, consultations with native doctors and diviners, and the lack of an established market for local livestock ethno-veterinary products. It is a consequence of these factors that the practice of ethno-veterinary medicine is strongly associated with low-income countries, where many livestock owners, especially in rural communities hosting the majority of livestock numbers, depend on indigenous or traditional beliefs, knowledge, skills and practices which pertain to the healthcare of animals.

However, among better resourced or commercial livestock farmers, the recourse to 
ethno-veterinary practices is not reported in the literature. Among this group of livestock farmers, many solely depend on established global bio-medicinal applications which originate from western scientific principles and products (Ahmad et al., 2015; Caudell et al., 2016). Wedged between the better resourced commercial livestock farmers and the highly resource-constrained rural subsistent livestock farmers, are the smallholder or emerging livestock farmers who utilize a mix of bio-medicine and ethnoveterinary practices, or medical pluralism. Mudzengi et al. (2014) averred that among this group of livestock owners, ethnoveterinary practices are mostly used in combination with pharmaceuticals rather than exclusively. Using the mixture of both 'medicines' has a long history among rural farmers in low-income countries (Carruth, 2014), and the relationship might either be complementary or competitive (MathezStiefel, 2012).

\section{Conclusion}

The foregoing hence lends credence to the perception or viewpoint that ethno-veterinary practice in low-income countries generally finds application among poorly-resourced subsistent and smallholder livestock farmers, whom might not be knowledgeable about, unable to access, or afford the cost of western medicines and associated veterinary services. Kambizi (2019) also concurred with this position, and exemplified that though conventional acaricides are well-suited for the treatment of ticks in livestock, it was considered to be unavailable or unaffordable among rural farmers, which resulted in the resort to alternative remedies and traditional methods. Notwithstanding that these plants and their concocts or derivatives are traditionally known to be useful in the management of vectors transmitting veterinary disease pathogens, their usefulness in terms of efficacy, effectiveness and other parameters of reliability and measurement are an on-going subject of contestation.

Meanwhile, the debate around ethnoveterinary medicine and practice provides a basis for advancing the research on the efficacy of derived ethno-products which might lead to the discovery of valuable organic pharmacological agents. Considering the huge amounts of synthetic antimicrobial agents utilized for treating various livestock species, Marshall and Levy (2011) posits the possibility for cross-contamination of resistant strains of zoonotic pathogens, which could lead to the development of resistance to drugs. This necessitates the prudent use of antimicrobials and antibiotics in treating livestock, and requires the acceptance of treatment and management practices that minimize or supplant the need for synthetic remedies. Resulting from this, Speksnijder and Wagenaar (2018) professed the extensive knowledge which is available to significantly eradicate or diminish the burden of different livestock infections and diseases, in the absence of antimicrobial and antibiotics usage for livestock production. In line with this, herbs, leaves and barks are known to be broad spectrum in action, an indicator that ethno- 
veterinary medicine provides both a practical choice and existing alternative.

\section{Reference}

Abdalla, M.A. and McGaw, L.J. 2020 Ethnoveterinary Medicine: Present and Future Concepts. in McGaw and Abdalla (eds.) Springer Nature, Switzerland 2020.

Ahmad K, Ahmad M, Weckerle C. 2015. Ethnoveterinary medicinal plant knowledge and practice among the tribal communities of Thakht-e-Sulaiman Hills, West Pakistan. J Ethnopharmacol. 170: 275-83.

Caudell MA, Quinlan MB, Call DR, Quinlan RJ. 2016. Veterinary Antibiotic Use among Agro-pastoralists in Northern Tanzania. Washington State University; Pullman, Washington, USA.

Carruth L. 2014. Camel milk, amoxicillin, and a prayer: Medical pluralism and medical humanitarian aid in the Somali Region of Ethiopia. Soc Sci Med, 120: 405-12.

Chitura et al. 2018. Use of medicinal plants by livestock farmers in a local municipality in vhembe district, South Africa. Applied Ecology and Environmental Research, 16: 5.

Fouche G., Ellof JN., Wellington KW. 2018. Evaluation of South African Plants with Acaricide Activity against Ticks. International Journal of Pharmacological and Pharmaceutical Sciences, 11(6): 386-390.

Kambizi L. 2019. Indigenous plants for ethnoveterinary uses in the Pondoland, South Africa, Acta Horticulturae. 1125. ISHS 2016.2 DOI 10.17660/ActaHortic.2016.1125.40

Mudzengi C., Dahwa C., Skosana J. and Murungweni C. 2014. Promoting the Use of Ethnoveterinary Practices in Livestock Health Management in Masvingo Province, Zimbabwe. Ethnobotany Research and Application 2014, 12: 397-405.
Mafimisebi, T.E., Oguntade, A.E., Fajemisin, A.N. et al. 2012. Local knowledge and socioeconomic determinants of traditional medicines' utilization in livestock health management in Southwest Nigeria. $J$ Ethnobiology Ethnomedicine 8, 2 (2012). https://doi.org/10.1186/1746-4269-8-2).

Mathez-Stiefel S-L, Vandebroek I, Rist S. 2012. Can Andean medicine coexist with biomedical healthcare? A comparison of two rural communities in Peru and Bolivia. J Ethnobiol Ethnomed, 8:1.

Mayer M., Zbinder M., Vogl C., Ivemeyer S., Meier B. et al. 2017. Swiss ethnoveterinary knowledge on medicinal plants - a within-country comparison of Italian speaking regions with northwestern German speaking regions. Journal of Ethnobiology and Ethnomedicine (2017) 13:1

Marshall BM. and Levy SB. 2011. Food animals and antimicrobials: Impacts on human health. Clin Microbiol Rev. 2011, 24: 71833

Sanhokwe M., Mupangwa J., Masika P. and Muchenje V. 2016. Medicinal plants used to control internal and external parasites in goats. Onderstepoort Journal of Veterinary Research 83: 1 (2016), http://dx.doi.org/10.4102/ojvr.v83i1 .1016

Speksnijder David and Wagenaar Jaap. 2018. Reducing antimicrobial use in farm animals: how to support behavioral change of veterinarians and farmers. Animal Frontiers, 8(2): 4-9.

Wolff, C., Abigaba, S. and Sternberg Lewerin, S. 2019. Ugandan cattle farmers' perceived needs of disease prevention and strategies to improve biosecurity. BMC Veterinary Research 15, 208 (2019). Available at https://doi.org/10.1186/s12917-0191961-2). 